\title{
A CLINICO-ETIOLOGICAL STUDY OF PULMONARY HYPERTENSION IN ADULTS IN A RURAL TERTIARY CARE HOSPITAL
}

\author{
U. Kalyan1, R. Lakshmi Visruja², H. Mallikarjuna Swamy33, Srinivasa Rao ${ }^{4}$
}

1 Postgraduate Resident Department of General Medicine, PES Institute of Medical Sciences and Research, Kuppam, Andhra Pradesh, India.

${ }_{2}^{2}$ Assistant Professor, Department of General Medicine, PES Institute of Medical Sciences and Research, Kuppam, Andhra Pradesh, India. 3 Professor, Department of General Medicine, PES Institute of Medical Sciences and Research, Kuppam, Andhra Pradesh, India. ${ }^{4}$ Professor and HOD, Department of General Medicine, PES Institute of Medical Sciences and Research, Kuppam, Andhra Pradesh, India. ABSTRACT

\section{BACKGROUND}

Pulmonary hypertension (PH) is a devastating condition if left undiagnosed and untreated. It does not pertain to a single cau sative factor but represents a common pathway for various diseases. There are only a few studies on PH and hence the purpose of this study is to shed some light on the clinical profile and etiological factors of PH in adults.

\section{MATERIALS AND METHODS}

All patients who were between 21-60 years of age, who presented with symptoms and signs of PH were included in this study; later confirmed with transthoracic echocardiography (TTE). Relevant data was collected and analysed.

\section{RESULTS}

Adults (21-60 years), 57 patients were included in this study. The mean age was $49 \pm 7.9$ years with male preponderance (64\%). Dyspnoea was the most common complaint seen in all subjects, followed by oedema (87.7\%) and jugular venous pressure rise $(80.7 \%)$ being the common signs. The most common independent etiological factor was chronic obstructive pulmonary disease (COPD) (35.1\%) followed by dilated cardiomyopathy (DCM) (33.3\%) where as the most common group was group 2 (47.4\%) according to World Health Organisation (WHO) classification.

\section{CONCLUSION}

$\mathrm{PH}$, being uncommon is a challenging disease, requires sufficient experience of physicians for a clinical suspicion. Since its cause is multifactorial, it can be difficult to arrive at the dominant cause and hence needs a meticulous approach to reach a diagnosis. A physical examination with a simple non-invasive echocardiogram will give useful information about diagnosis and severity of the disease.

\section{KEY WORDS}

Pulmonary Hypertension, TTE, COPD, DCM

HOW TO CITE THIS ARTICLE: Kalyan U, Visruja RL, Swamy HM, et al. A clinico-etiological study of pulmonary hypertension in adults in a rural tertiary care hospital. J. Evolution Med. Dent. Sci. 2019;8(10):685-688, DOI: 10.14260/jemds/2019/152

\section{BACKGROUND}

Pulmonary Hypertension (PH) is one of the most debilitating cardiovascular disease. It is a disorder of pulmonary vasculature which is progressive and is associated with significant morbidity and mortality if left untreated. Even though this disease has nearly 100 years' history, most of the knowledge has evolved in the past two decades.(1)

$\mathrm{PH}$ is defined as a mean pulmonary artery pressure (mPAP) $\geq 25 \mathrm{~mm} \mathrm{Hg}$ at rest and is clinically classified into five groups based on World Health Organisation (WHO) classification \{Pulmonary arterial hypertension (PAH)- Group 1 , associated to congenital heart diseases or disorders of left side of heart- Group 2, associated to lung disorders or hypoxia- Group 3, chronic pulmonary thromboembolismGroup 4 and miscellaneous- Group 5\} based on the predominant underlying pathology.(2,3,4)

'Financial or Other Competing Interest': None.

Submission 18-01-2019, Peer Review 21-02-2019,

Acceptance 28-02-2019, Published 11-03-2019.

Corresponding Author:

Dr. R. Lakshmi Visruja,

Assistant Professor, Department of General Medicine,

PESIMSR, Kuppam-517425, Andhra Pradesh, India.

E-mail: visruja@gmail.com

DOI: $10.14260 /$ jemds $/ 2019 / 152$

(c) $($ ) $\$$
The main pathophysiology being extensive obliterative changes that occur in small to midsized pulmonary arteries. The alterations in structure and function of the endothelium in conjunction with the growth of neointimal, medial, and adventitial layers, culminates in an occlusive arteriopathy causing high resistance to blood flow leading to right heart failure and death.(5) PH does not pertain to a single causative factor but represents a multitude of diseases/pathologies. Most of the time the symptoms are non-specific and most often are related to the progression of right ventricular (RV) dysfunction. With the advent of the new era of advanced diagnostic procedures, the condition has become more evident and can be diagnosed non-invasively.

There are fewer studies on PH around the world and are even less in India comparatively, the earliest being the National Institute of Health Registry in the United States started in 1981. The studies done in developed countries attribute heart failure as the most common cause of $\mathrm{PH}$, (6) whereas it is post-infectious sequelae in developing countries like India.(7) As the disease is becoming more and more evident in day to day practice, thanks to the recent advances, it is believed that there is a need to study PH in the Indian population, so as to decrease the morbidity and mortality associated, thereby improving the quality of life. The present study aims at studying the clinical profile and etiology of $\mathrm{PH}$ in the adult population in a rural tertiary care hospital. 


\section{MATERIALS AND METHODS}

\section{Study Design}

Descriptive study.

The study was conducted at PES (Peoples Educational Society) institute of medical sciences and research hospital (PESIMSR), Kuppam, Andhra Pradesh, South India after obtaining the Hospital Ethical Committee clearance. All the patients who were admitted and diagnosed as $\mathrm{PH}$, who satisfied the inclusion criteria were selected, over a period of 12 months. This simple observational and descriptive study was carried out on 57 patients who presented to PESIMSR with signs and symptoms of PH during the study period (2017 - 2018). Sample size was taken based on the convenience of the study

An elaborated history of events regarding onset, frequency and etiological clues, past history as well as previous hospitalizations through old medical records were recorded. A complete general and systemic examination with detailed cardiovascular and respiratory system examination was carried out. In addition to the routine laboratory investigations, chest radiograph (CXR), electrocardiography (ECG), and echocardiogram were done. All patients were subjected to a complete transthoracic echocardiographic study including two-dimensional, M Mode, and colour flow Doppler. The grading of dyspnoea was done according to New York Heart Association classification (NYHA).(8) The subjects were divided into groups based on WHO classification.

\section{Inclusion Criteria}

- Patients aged more than or equal to 21 years to 60 years.

- Patients with clinical and documented features of pulmonary hypertension.

\section{Exclusion Criteria}

Nil.

All the cases were followed up until discharge or otherwise.

\section{Statistical Analysis}

All results were recorded, tabulated and analysed using appropriate statistical methods. The data were analysed using SPSS version 17 for windows.

\section{RESULTS}

The present study was conducted on 57 patients diagnosed as pulmonary hypertension.

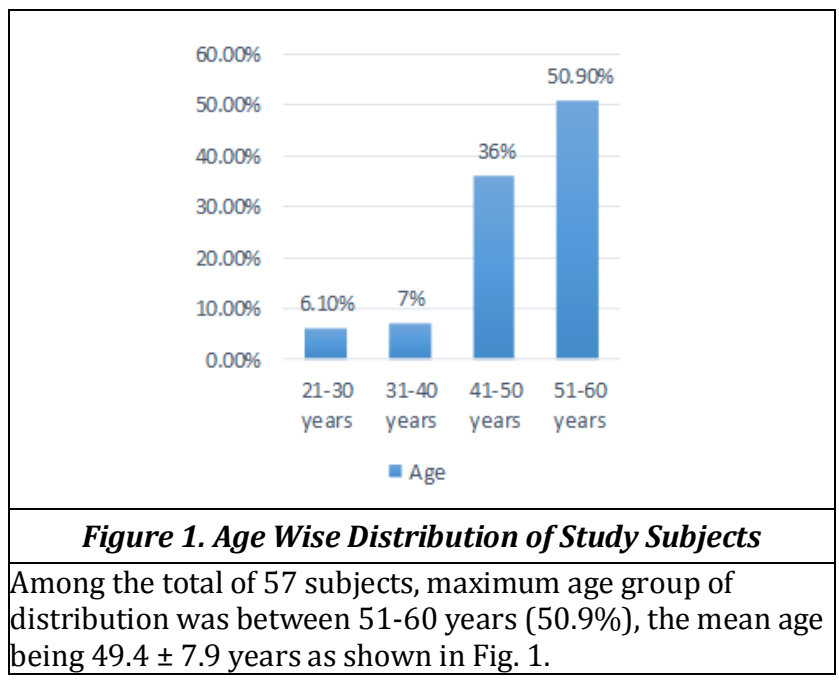

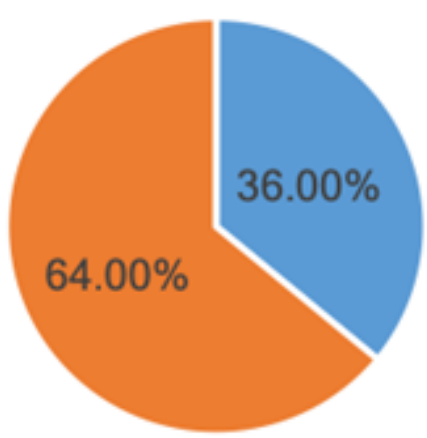

" Females $=$ Males

Figure 2. Gender Wise Distribution of Study Subjects As shown in Fig 2, males were 64\% and females 36\% with male: female ratio being 1.8:1.

\begin{tabular}{|c|c|c|}
\hline Symptom/Sign & Frequency & Percent \\
\hline Dyspnoea & 57 & $100.0 \%$ \\
\hline Oedema & 50 & $87.7 \%$ \\
\hline Raise in Jugular venous Pressure & 46 & $80.7 \%$ \\
\hline Wheeze & 42 & $75.4 \%$ \\
\hline Crepitations & 35 & $61.4 \%$ \\
\hline Cyanosis & 28 & $50.0 \%$ \\
\hline Ascites & 14 & $23.7 \%$ \\
\hline Clubbing & 5 & $8.8 \%$ \\
\hline Pallor & 3 & $5.3 \%$ \\
\hline Syncope & 2 & $3.5 \%$ \\
\hline
\end{tabular}

Table 1. Symptoms and Signs of Study Subjects

As shown in table 1, in the present study the most common symptom was dyspnoea which was seen in $100 \%$ of the study subjects, followed by oedema (87.7\%) and Jugular venous pressure rise seen in $80.7 \%$.

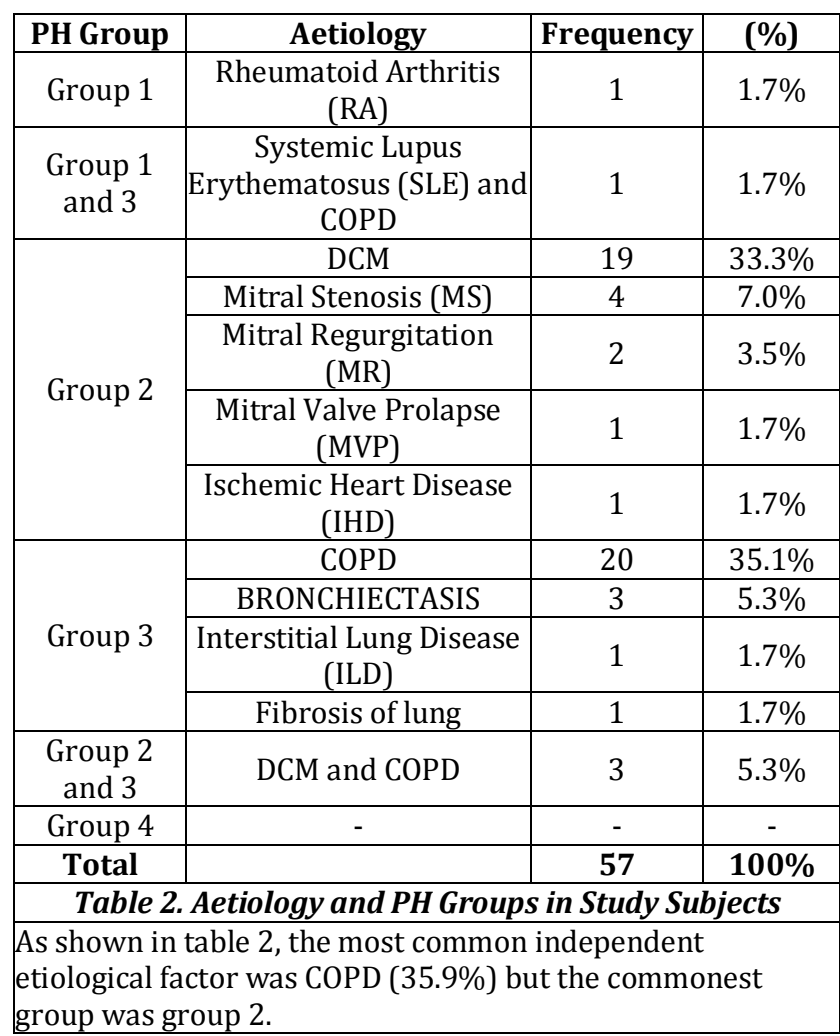




\begin{tabular}{|c|c|c|c|}
\hline \multicolumn{1}{|c|}{} & Frequency & Percent \\
\hline \multirow{4}{*}{ PH Group } & Group 1 & 1 & $1.7 \%$ \\
\cline { 2 - 4 } & Group 1, 3 & 1 & $1.7 \%$ \\
\cline { 2 - 4 } & Group 2 & 27 & $47.4 \%$ \\
\cline { 2 - 4 } & Group 2, 3 & 3 & $5.3 \%$ \\
\cline { 2 - 4 } & Group 3 & 25 & $43.9 \%$ \\
\cline { 2 - 4 } & Total & $\mathbf{5 7}$ & $\mathbf{1 0 0 . 0 \%}$ \\
\hline Table 3. Classification of Pulmonary Hypertension \\
in Study Subjects \\
\hline $\begin{array}{c}\text { Among all the 57 subjects, 27 (47.4\%) belong to Group 2 } \\
\text { followed by 25 (43.9\%) belonging to Group 3 as shown in } \\
\text { table 3. }\end{array}$ \\
\hline
\end{tabular}

\section{DISCUSSION}

Studies concerning pulmonary hypertension are limited in India. Exact incidence and prevalence are not calculated since it is a hospital-based study. In the total of 57 patients studied, the most common group affected in this study was in the $5^{\text {th }}$ and $6^{\text {th }}$ decades of life. In a study by Lam et al, the increase in pulmonary artery pressure was coupled with an increase in pulse pressure and estimated left heart filling pressures, suggesting that age-associated blood vessel stiffening and diastolic dysfunction contribute to changes in pulmonary artery pressure.(9)

In the present study, the mean age was $49.4 \pm 7.9$ years as compared to $42.5 \pm 15.4 .(7)$ and $35.6 \pm 14.3(10)$ in other studies. Overall there was a male preponderance $(64 \%)$ in this study. Similar results (54\%) were shown in a study conducted by Bansal et al.(7) and almost equal male: female ratio was observed (49.1\% males) in an another study by Mehrotra et al.(10) The male: female ratio in this study was 1.8: 1. This may be due to smoking in men, and it is an important predisposing factor for COPD which is one of the important causes of $\mathrm{PH}$.

Systemic hypertension and diabetes mellitus showed no significant association with $\mathrm{PH}$ in the present study. Patients who had pulmonary tuberculosis and bronchiectasis in the past were almost $100 \%$ associated with $\mathrm{PH}$ which suggested that post-infectious sequelae are an essential cause of PH. Similar results were found in the study conducted by Bansal et al.(7)

Most patients in this study shared the same clinical presentation. Exertional dyspnoea and fatiguability were the most common clinical manifestations in the study subjects. Hundred percent of our patients had dyspnoea as the most common presenting complaint comparable to $85.8 \%{ }^{(7)}$ and $82.5 \%(10)$ in other studies. Most of them $(49.1 \%)$ presented with Grade IV dyspnoea (NYHA classification) with $59.6 \%$ of them having orthopnea.

In this study, on systemic examination the heart sounds in most of the patients were muffled (41.2\%) and loud and palpable pulmonary component of second heart sound (P2) was noted in $18.4 \%$ of the subjects. Loud and palpable P2 had both high sensitivity and specificity in diagnosing $\mathrm{PH}$ in our study. The loud pulmonary component of second heart sound was observed in $72 \%(7)$ and $44.4 \%^{(10)}$ in other studies denoting its high sensitivity and specificity.

\begin{tabular}{|c|c|c|c|c|}
\hline & $\begin{array}{l}\text { Present } \\
\text { Study }\end{array}$ & $\begin{array}{c}\text { Bansal } \\
\text { et al. }\end{array}$ & $\begin{array}{c}\text { Mehrotra } \\
\text { et al. }\end{array}$ \\
\hline \multicolumn{2}{|c|}{ Mean Age (Years) } & $49.4 \pm 7.9$ & $42.5 \pm 15.4$ & $35.6 \pm 14.3$ \\
\hline \multirow{2}{*}{ Gender } & Males & $64 \%$ & $54 \%$ & $49.1 \%$ \\
\hline & Females & $36 \%$ & $46 \%$ & $50.9 \%$ \\
\hline \multicolumn{2}{|c|}{ Dyspnoea } & $100 \%$ & $85.8 \%$ & $82.5 \%$ \\
\hline \multicolumn{2}{|c|}{$\begin{array}{c}\text { Loud P2 in } \\
\text { Pulmonary Area (PA) }\end{array}$} & $18 \%$ & $72 \%$ & $44.4 \%$ \\
\hline \multicolumn{5}{|c|}{ Table 4. Comparison Between Studies } \\
\hline
\end{tabular}

In this study, the common independent etiological factor/ pathology for PH was COPD (35.1\%) closely followed by DCM $(33.3 \%)$. According to the updated classification of pulmonary hypertension (NICE 2013), these belong to group 3 and group 2 respectively.

The severity of the PH was associated with LVEF. In the current study, less the LVEF- more severe the symptoms and $\mathrm{PH}$, as was observed in the earlier studies.(11,12)

Despite COPD being the most common independent etiological factor, Group $3 \mathrm{PH}$ (43.9\%) was the second commonest etiological group in the present study which was different from an observational study conducted by Bansal et.al, in which post infectious obliterative bronchiolitis (30\%) was observed to be the most common cause of $\mathrm{PH}$ in the Indian population followed by ILD (28.5\%), COPD (24\%), Obstructive Sleep Apnoea (12.5\%), HIV (1.8\%), and PAH $(1.5 \%) .{ }^{(7)}$ The above difference may be due to a multitude of factors such an eclectic selection of population group and small sample size.

\section{Limitations}

The present study had a few limitations as the sample size was small (57 patients). Population group was heterogeneous in terms of age, gender, history of risk factors and exposure. Invasive pulmonary pressure measurement could not be done.

\section{CONCLUSION}

$\mathrm{PH}$, being uncommon is a challenging disease, requires sufficient experience of physicians for a clinical suspicion. Since its cause is multifactorial, it can be difficult to arrive at the dominant cause and hence needs a meticulous approach to reach a diagnosis. A physical examination with a simple non-invasive echocardiogram will give useful information about diagnosis and severity of the disease.

\section{REFERENCES}

[1] Romberg E. Ueber Sklerose der Lungen arterie. Dtsch Archiv Klin Med 1891;48:197-206.

[2] Simonneau G, Galiè N, Rubin LJ, et al. Clinical classification of pulmonary hypertension. J Am Coll Cardiol 2004;43(12 Suppl S):5S-12S.

[3] Simonneau G, Robbins IM, Beghetti M, et al. Updated clinical classification of pulmonary hypertension. J Am Coll Cardiol 2009;54(1 Suppl):S43-S54.

[4] Simonneau G, Gatzoulis MA, Adatia I, et al. Updated clinical classification of pulmonary hypertension. J Am Coll Cardiol 2013;62(25 Suppl):D34-D41.

[5] Tuder RM. How do we measure pathology in PAH (lung and RV) and what does it tell us about the disease? Drug Discov Today 2014;19(8):1257-63. 
[6] Lam CS, Roger VL, Rodeheffer RJ, et al. Pulmonary hypertension in heart failure with preserved ejection fraction: a community-based study. J Am Coll Cardiol 2009;53(13):1119-26.

[7] Bansal S, Utpat K, Desai U, et al. Clinical profile of pulmonary hypertension at a tertiary care centre, India. European Respiratory Journal 2017;50: PA2439.

[8] The Criteria Committee of the New York Heart Association. Nomenclature and criteria for diagnosis of diseases of the heart and great vessels. $9^{\text {th }}$ edn. Boston, Mass: Little, Brown \& Co., 1994: p. 253-6.

[9] Lam CS, Borlaug BA, Kane GC, et al. Rodeheffer RJ, Redfield MM. Age-associated increases in pulmonary artery systolic pressure in the general population. Circulation 2009;119(20):2663-70.
[10] Mehrotra R, Bansal M, Kasliwal RR, et al. Epidemiological and clinical profile of pulmonary hypertension: Data from an Indian Registry. Journal of Clinical and Preventive Cardiology 2012;2:51-7.

[11] Ghio S, Gavazzi A, Campana C, et al. Independent and additive prognostic value of right ventricular systolic function and pulmonary artery pressure in patients with chronic heart failure. J Am Coll Cardiol 2001;37(1):183-8.

[12] Abramson SV, Burke JF, Kelly JJ Jr, et al. Pulmonary hypertension predicts mortality and morbidity in patients with dilated cardiomyopathy. Ann Intern Med 1992;116(11):888-95. 